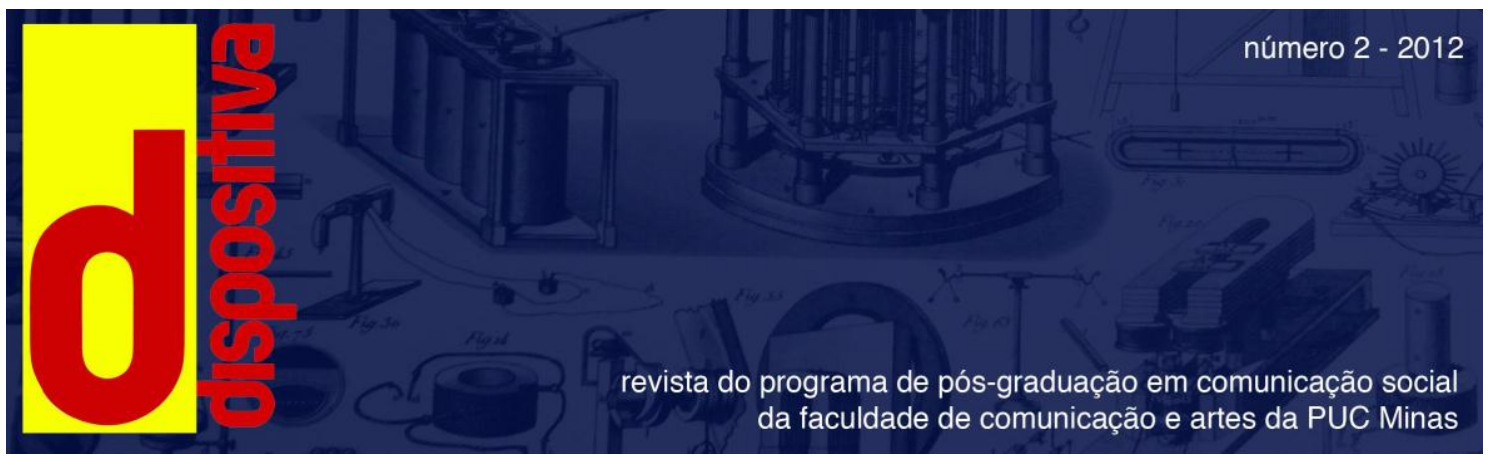

\title{
A infografia jornalística como recurso de visibilização da realidade da construção// The journalistic infographics as as visualizer construction of reality ${ }^{1}$
}

Ricardo Jorge de Lucena Lucas ${ }^{2}$

\section{Resumo}

O presente artigo discute aspectos que permitem perceber a infografia como um novo locus que possibilita a criação de vínculos entre jornalistas e leitores; defendemos que ela se constitui em um novo tipo de recurso de visibilização dos processos classificados por Antonio Fausto Neto como "realidade da construção". Para tal, são levados em conta o suposto papel metanarrativo do sistema midiático na contemporaneidade e a autorreferencialidade presente em seus enunciados e produtos simbólicos.

Palavras-chave: Infografia; jornalismo; autorreferencialidade; vínculo; realidade da construção.

\begin{abstract}
:
This paper discusses aspects that allow to perceive infographics as a new locus that enables the creation of links between journalists and readers. We argue that it constitutes a new type of resource visualization of processes sorted by Antonio Fausto Neto as "reality of construction". To do so, the supposed metanarrative role of the media system and the self-referentiality present in their statement and symbolic products are taken into account.
\end{abstract}

Keywords: Infographics; journalism; self-referentiality; link; reality of construction.

\section{Introdução}

É comum pensar-se no uso da infografia no jornalismo como um modo a mais (e mais eficiente) de descrever a realidade social em suas várias vertentes (científica, esportiva, econômica etc.), através dos processos de reconstituição ou de visualização. Ao mesmo tempo, o uso do recurso infográfico pode fazer parte do universo das

\footnotetext{
${ }^{1}$ Trabalho apresentado no VII Encontro Nacional de Pesquisadores em Jornalismo, ocorrido na USP em 2009 e promovido pela SBPJor (Associação Brasileira de Pesquisadores de Jornalismo). A versão aqui apresentada traz algumas poucas alterações.

${ }_{2}^{2}$ Professor de Jornalismo e Publicidade do Instituto de Cultura e Arte da Universidade Federal do Ceará (ICA-UFC), Doutor em Comunicação pela Universidade Federal de Pernambuco (UFPE) e jornalista.
} 
estratégias discursivas de credibilidade, as quais visam apontar provas de veracidade dos fatos expostos e da pertinência das explicações expostas (CHARAUDEAU, 2006, 55-6, 87-91; LOCHARD \& BOYER, 2004, 65) desde que, a nosso ver, montadas com imagens alográficas ${ }^{3}$ fotográficas e fac-símiles de documentos (LUCAS, 2010).

Se o texto escrito jornalístico (com a ausência textual do narrador e a descrição pormenorizada dos fatos, por exemplo) e a fotografia jornalística (com a ausência visual do agente enunciador, o fotógrafo) contribuem para a construção de um maior efeito de realidade, as infografias jornalísticas, graças a certos recursos visuais (perspectiva, proporcionalidade), são por vezes percebidas como um locus no qual os efeitos de objetividade e cientificidade ganham novas possibilidades (justamente por tomarem de empréstimo recursos visuais de áreas com status científico: Estatística, Cartografia, Biologia). Lorenzo Gomis, por exemplo, lembra que a estatística "é o registro indiscutível e exato da presença anônima" (GOMIS, 1997, 119. Grifo nosso).

Além disso, a infografia não só é fruto da crescente informatização das redações nos anos 1980/90, mas também fruto de um discurso a respeito da própria infografia que podia se tornar uma ferramenta a serviço do jornalismo; tal discurso podia se dar dentro das redações ou na superfície do próprio sistema midiático. Há um investimento de sentido na infografia para que ela possa se tornar uma matéria significante relevante, no âmbito das redações (até então, solidamente estabelecidas em torno do texto verbal e, mais recentemente, da fotografia e das cores) e junto ao leitorado.

O que pretendemos discutir aqui são outras possibilidades dos textos infográficos. Uma delas é pensá-los como espaços nos quais pode ocorrer aquilo que Antonio Fausto Neto (baseado em Niklas Luhmann) chama de "a realidade da construção" (em uma espécie de "oposição complementar" ao conceito de "construção da realidade"); outra possibilidade é percebê-los como um novo espaço de construção de vínculos, assimétricos, complementares (BATESON, 1977, 98-100), mas que visam estabelecer "vínculos de confiança" (FAUSTO NETO, 2006, 46). Em suma: pensar a infografia para além de seus efeitos de objetividade e cientificidade. Dentro desse tipo particular de processo midiático de investimento de sentido na infografia como recurso crível de informações jornalísticas, localizamos dois momentos pertinentes para nossas reflexões.

\section{Aspectos teóricos}

\footnotetext{
${ }^{3}$ Conforme expressão de Nelson Goodman. Linguagens da Arte - uma abordagem a uma teoria dos símbolos. Lisboa: Gradiva, 2006.
} 
A infografia ganha espaço num momento coincidente e curioso: o do ápice da discussão acerca do pós-moderno (são apenas cerca de dois anos de diferença entre a publicação original de $O$ Pós-Moderno de Jean-François Lyotard e o surgimento do jornal norte-americano USA Today). Mesmo que a discussão sobre o pós-moderno tenha perdido força (diante da "modernidade líquida", do "contemporâneo" e de outras expressões afins), é fato que muitos não acreditam mais totalmente no caráter universalizante (e eurocêntrico) das grandes narrativas (ou pelo menos de parte delas). Relativizamos o conceito de pós-moderno, mas talvez não necessariamente tenhamos relativizado suas ideias $\mathrm{e}$ as consequências dele decorrentes. $\mathrm{O}$ local, o microssociológico, o subalterno, todos eles passam a ter direito a uma existência conceitual, a uma definição, a um locus. Paradoxalmente, a nosso ver, surge uma nova tentativa de grande narrativa, que tenta dar sentido a tudo (ou, pelo menos, a tudo que ela própria considere relevante): essa tentativa parece ser esboçada (não sem conflitos) pelo sistema midiático contemporâneo através de seus produtos (noticiários, programas de entretenimento, reality shows etc.). O sistema midiático converte-se, cada vez mais, num espaço que busca legitimação junto a outros espaços simbólicos e instituições. Ao mesmo tempo, o sistema midiático é um espaço no qual as instituições (políticas, econômicas, culturais, sociais) são legitimadas ou deslegitimadas, através de movimentos específicos a esse universo (estratégias de agendamento, silenciamento e enquadramento), mas também através de estratégias discursivas (de narração, descrição, modalização etc.), tanto para se referirem a essas instituições quanto para se referirem a si próprias (nesse caso, através de discursos autolegitimantes e/ou autorreferenciais).

Há, porém, aparentemente, apenas uma diferença significativa: se as demais metanarrativas (Catolicismo, Capitalismo, Comunismo, Socialismo) têm como base de seus projetos a Utopia ${ }^{4}$, a ação futura, a metanarrativa midiática tem como base apenas o tempo presente, sua ação é a do aqui e agora; a utopia da comunicação midiática é, paradoxalmente, não visar nenhuma utopia, nenhum projeto a não ser o da visibilização (pretensamente) total dos fatos do mundo. A mídia visibiliza projetos e utopias de outras metanarrativas, mas não tem o seu próprio projeto (no sentido moderno do termo), de algum modo tudo é um puro hic et nunc visibilizado, mostrado, narrado, flagrado. $\mathrm{O}$ sistema midiático se torna um epicentro metanarrativo (mas não o

\footnotetext{
${ }^{4}$ Utopia essa que atende por diversos nomes, conforme a metanarrativa em questão: o Reino do Amanhã, o acúmulo de capital, a sociedade sem classes, a inevitabilidade do proletariado no poder...
} 
único, na prática). Essa relação entre o sistema midiático e a "dissolução da modernidade" e das metanarrativas tradicionais é pensada em alguns autores (VATTIMO, 1991; RINCÓN, 2006).

Além disso, novas modalidades de relação entre sujeitos e equipamentos técnicomidiáticos estão surgindo. A crescente popularização e facilitação no uso de equipamentos tecnológicos digitais (computadores, filmadoras, máquinas fotográficas) estabelecem um "redesenho" no que diz respeito a quem detém as "capacidades instrumentais" na produção de enunciados midiatizáveis e/ou midiatizados. O domínio da técnica (ou de uma parte suficiente dela) permite que qualquer pessoa, em tese ${ }^{5}$, possa fazer registros fotográficos, criar blogs, filmar etc. $\mathrm{O}$ fazer midiático (profissional) torna-se cada vez mais um fazer cotidiano, e as práticas daí recorrentes também se tornam cotidianas. Com isso, o sujeito outrora "passivo" (ao menos supostamente, diante dos meios de comunicação de massa) passa, aos poucos, a pensarse também como sujeito "mais ativo, porque mais participativo".

No que diz respeito ao jornalismo, isso cria uma nova espécie de relação entre jornalistas e leitores. Antes o leitor era visto como um sujeito que tinha uma "capacidade seletiva" (Joseph T. Klapper) para optar diante das possibilidades de oferta midiática (a percepção seletiva); depois, passou a ser visto como parte essencial da constituição do sentido dos enunciados midiáticos (a competência interpretativa) (Umberto Eco); atualmente, ele deve dominar (também) os recursos que o circuito midiático disponibiliza a ele (a habilidade técnico-enunciativa) através das diversas possibilidades de vínculo (bate-papo com entrevistados após um programa da TV, comentários em portais jornalísticos, envio de fotos e/ou vídeos caseiros com suposto valor informativo etc.).

É dentro desse cenário que o jornalismo impresso tenta sobreviver ou se "reinventar". Se o rádio e a TV permitiam ao ouvinte/espectador o contato através de telefonema ou carta, as tecnologias digitais permitem outras vias de contato e

\footnotetext{
${ }^{5}$ Não queremos sugerir uma espécie de "simplismo invertido": se antes, por exemplo, acreditava-se (muitos ainda acreditam até hoje) no poder de "transparência enunciativa" das imagens (supostamente mais eficientes do que os textos escritos), hoje não queremos cair no risco de dizer que há uma "transparência enunciatória", ou seja, de que qualquer um pode fazer fotos, textos, vídeos etc., uma vez que a ideia (utópica) de uma sociedade totalmente midiatizada ainda está longe de atingir a todas as pessoas, efetiva e indistintamente; além disso, existem diferentes modalidades (escrever, fotografar, filmar, editar etc.) e certas regras, ligadas aos aspectos sociais e profissionais do jornalismo (por exemplo), que implicam em diferentes tipos de textos finais. Em suma: um leitor, um blogueiro e um jornalista, em tese, dificilmente construirão um dado texto jornalístico segundo as mesmas regras e modalidades (competência textual e/ou visual, regras do fazer jornalístico, situações de interação com as fontes etc.).
} 
estabelecimento de vínculo. Ao jornalismo impresso, restam alguns problemas, como a inexistência de um contato em "tempo real" (a temporalidade dos meios impressos é distinta da dos meios eletrônicos e digitais) e o fato de que o texto jornalístico escrito, por questões industriais, está atrelado a uma "fôrma" única, amarrado a projetos gráficos que raramente permitem liberdades estéticas ao texto escrito.

Assim, a infografia irrompe como uma outra tentativa de estabelecer novos e/ou diferentes vínculos entre leitor e jornalismo impresso. De um lado já havia uma constância visual monocórdica nas matérias jornalísticas; de outro, o uso de recursos visuais em relação de contraste com as matérias, como os títulos/manchetes, fotos e desenhos, em "disputa” (de espaço e de sentido) com os anúncios publicitários. Agora, o crescimento de premiações na área de desenho jornalístico (projetos gráficos, capas etc.) tem feito com que as redações se preocupem (ainda que de diferentes modos) com a apresentação gráfica de seus textos e primeiras páginas (figura 1).
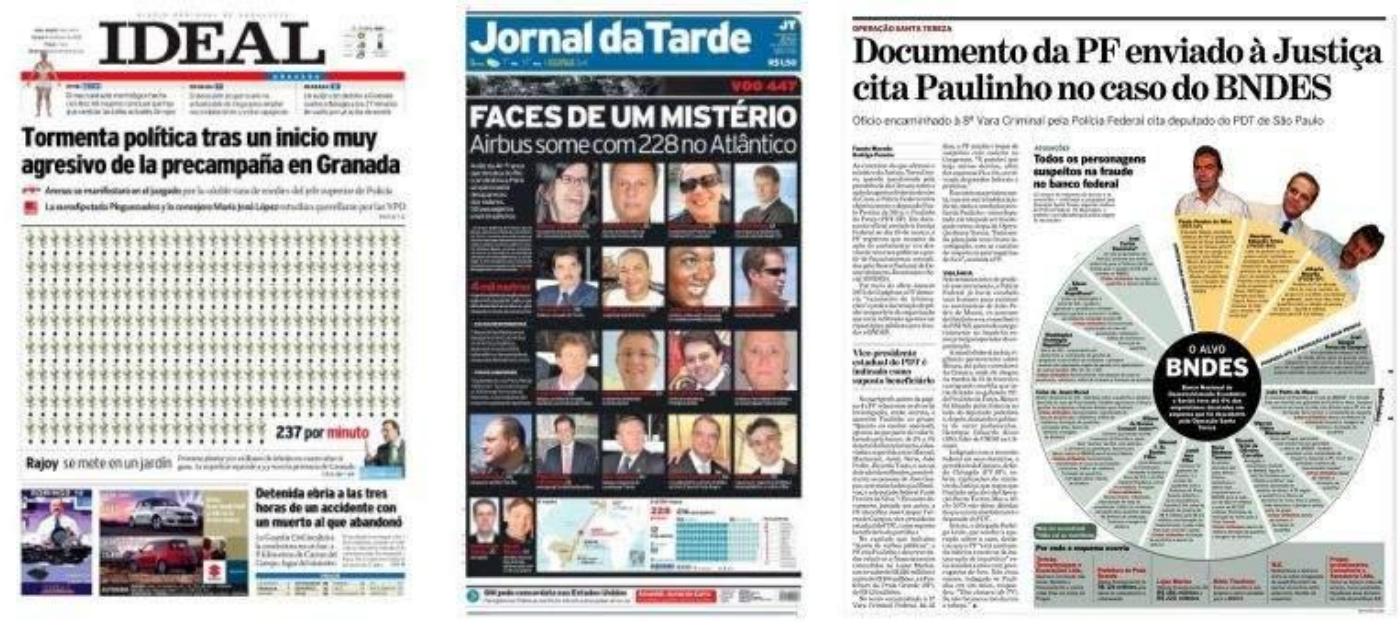

Fig. 1 - Capas do Ideal (Espanha) e Jornal da Tarde (Brasil) e página do O Estado de São Paulo

Com isso, ao sistema midiático atual, em particular ao jornalismo, não basta mais apenas classificar, descrever, hierarquizar, categorizar, selecionar, omitir e visibilizar falas e opiniões de vozes autorizadas; é preciso também (e mais do que nunca) explicar, não apenas textualmente, nem apenas visualmente; é preciso ainda tentar uma descrição mais detalhada, que explique tanto o macroscópico quanto o microscópico, que descreva tanto aquilo que foi quanto aquilo que virá a ser. É nesse contexto, em nossa visão, que o recurso infográfico vem ganhando espaço: se o texto explica, narra e conceitua e a fotografia mostra, a infografia pode fazer tudo isso 
(descrever, narrar, conceituar e mostrar, além de articular aquilo que aparentemente está "solto no mundo"). Como afirma Maurice Mouillaud, o jornal, ao buscar um "trabalho de coerência no espaço", "produz esquemas que substituem o caos da explosão por uma topografia nítida e distinta" (MOUILLAUD, 1997, 50). Assim, é preciso descrever, num mundo tido como cada vez mais complexo ${ }^{6}$ e multi/inter/transdisciplinar, pautado por elementos pertencentes a um universo microscópico (nanotecnologia, biomedicina, microinformática) e também por problemas globais e macroscópicos (aquecimento do planeta, poluição ambiental, esgotamento dos recursos naturais, crises econômicofinanceiras em larga escala). Não à toa, Fausto Neto $(2006,47)$ fala, ao abordar os processos de midiatização na atualidade, em uma "pedagogia interpretativa".

Devemos lembrar que, para que essa "pedagogia interpretativa" ocorra, é preciso haver não apenas a aceitação de um pacto de referencialidade ${ }^{7}$ por parte do leitor em relação a um determinado veículo; é necessário também que se estabeleça um "contrato" entre enunciador (jornal) e destinatário (leitor), no qual o jornal se apresente como um "sujeito semiótico" que enuncia/anuncia dentro de determinadas características enunciativas (tipo de diagramação, uso ou não de cores, uso de tipias elegantes ou populares, modos de titulação etc.) as quais não podem ser, de algum modo, quebradas (salvo exceções anunciadas, como reformas gráficas, ou acontecimentos excepcionais, como a morte de personalidades ou autoridades, a conquista ou perda de um importante evento esportivo etc.). Dentro desse contrato, o leitor deve "aceitar" que o jornal possa ser reconhecido como (também) uma "instância pedagógica". Obviamente, os modos como uma infografia é produzida fazem parte desse "contrato".

\section{A autorreferencialidade midiática}

\footnotetext{
${ }^{6}$ Sobre a dita complexidade do mundo, Charaudeau (2006) lembra o seguinte: "deve-se notar que a ideia segundo a qual as sociedades modernas são cada vez mais complexas é uma ideia que, por ser muito difundida, não deixa de ser relativa a um ponto de vista - o do homem atual. Mas pode-se apostar - na impossibilidade de demonstrá-lo - que o homem do Renascimento, e posteriormente aquele dos séculos XVIII e XIX, deviam considerar que as sociedades são cada vez mais complexas, isto é, cada vez menos inteligíveis, o que conduz ao paradoxo, já que a ciência está cada vez mais desenvolvida e a tecnologia cada vez mais sofisticada, permitindo ao homem, ao que parece, melhor dominar este mundo. Em relação a esse paradoxo, trata-se de uma confusão entre o que é o mundo e o que é o saber que se tem sobre o mundo. O mundo - e o mesmo ocorre nas sociedades - é apenas o mundo; não é simples nem complexo. É o saber sobre o mundo que permite descobrir - oh, paradoxo! - sua complexidade. Isso é verdadeiro para todas as épocas" (CHARAUDEAU, 2006, 264).

${ }^{7}$ Baseamo-nos abertamente nas ideias de Phillipe Lejeune (2002) acerca do pacto entre leitor e obra autobiográfica para que o primeiro aceite o texto como referencial. O mesmo deve ocorrer entre leitores e jornais.
} 
O sistema midiático abre um novo front de explicações: não apenas falar sobre si próprio, mas também explicar as suas próprias operações de funcionamento enunciativo. Fausto Neto, baseado nas ideias de Niklas Luhmann sobre a realidade da construção, analisa seções de cartas de leitores de revistas semanais brasileiras e percebe que

\begin{abstract}
o trabalho enunciativo dos media já não mais se restringe a "construir realidade", mas deslocar a ênfase dessa tessitura para evidenciar a "realidade da construção". De uma maneira sintética, se passa de uma preocupação sobre o discurso jornalístico que centra sua atenção no trabalho textual, como operador de produção de realidades, para um novo momento em que se afirma que uma ênfase do trabalho da noticiabilidade está assim na própria narrativa em que se engendram as condições de "realidade de construção" (FAUSTO NETO, 2006, 51).
\end{abstract}

Isso implica não apenas (com o perdão da redundância) "noticiar a notícia", mas também visibilizar o processo de produção da notícia (reunião de pauta, procedimentos do jornalista, escolha das fontes). Assim, diz Fausto Neto, uma nova modalidade pragmática de vínculo entre jornalista e leitor passa a se estabelecer, uma vez que se desenham "novas modalidades de confiança / credibilidade / crença, como possibilidade de produção de um novo "regime de vínculos"” (FAUSTO NETO, 2006, 53). Assim, quando a imprensa fala sobre seus processos de produção, estaria em tese (e do ponto de vista da própria imprensa) atingindo o ápice da sua "transparência enunciativa", pois ela mostra inclusive os modos "técnicos" pelos quais ela constrói (ou melhor, como ela "reflete") a realidade ${ }^{8}$. Em suma: "não se perde nada" no trabalho jornalístico.

Porém, é preciso não confundir a autorreferencialidade da produção midiática com aquilo que Robert Ferguson chama de "autorreflexividade"; segundo esse autor, os discursos midiáticos quase nunca são autorreflexivos, pois eles se interrogam muito pouco sobre si próprios (exceto para autocongratulação) e quase sempre se centram no como, nunca no porquê a mídia faz as coisas como faz (quais as escolhas que toma e as que deixa de tomar, por exemplo) (FERGUSON, 2007, 53).

\title{
O material analisado
}

\footnotetext{
${ }^{8}$ A nosso ver, isso é consequência do sintoma de um processo comum na esfera televisiva, e que surge nos anos 1990, que é transformar a TV, antes uma "caixa mágica" de ilusões, em uma instância de "transparência total". Certas estratégias televisuais (como colocar os apresentadores de telenoticiários dentro das redações, as quais podemos ver) e certos programas (como o extinto programa infantil $T V$ Colosso, que mostrava como funcionava por dentro uma emissora de TV) dão mostras desse autocentramento. Hoje, programas como Profissão Repórter, que mostra como se faz uma reportagem televisiva, acabam por aproximar o espectador da televisão, que se torna cada vez mais para ele uma esfera "íntima".
} 
Tomemos dois exemplos distintos de como se dá essa "autorreferencialidade pedagógica”, especificamente envolvendo as infografias. Nos casos que temos em mãos, o que está em jogo não é como determinado enunciado jornalístico foi produzido, mas sim como um modo de enunciar jornalisticamente é produzido, ou seja, mostra-se a realidade de um dos modos de se construir. O mais curioso é que, nesses casos, há uma espécie de "dupla autorreferencialidade": o discurso jornalístico fala sobre o seu fazer enunciativo (ou seja, como fazer infografias), fala sobre como foi feita uma dada infografia produzida pelo próprio universo jornalístico (tanto que os exemplos são de infografias publicadas) mas, ao mesmo tempo, sua própria enunciação se dá num enunciado que se aproxima da estruturação da informação no infográfico. Ou seja: o discurso jornalístico fala sobre o seu fazer, fala sobre o que fez e mostra como fez o que fez "fazendo novamente".

\section{A infografia pedagógica: "é fazendo que ensinamos a fazer"}

Nosso primeiro exemplo (figura 2) vem da revista Mundo Estranho, publicação que é uma espécie de "desdobramento editorial" edição n. 76, de junho de 2008, página 20, na seção fixa "Superprofissão - o que você vai ser quando crescer?", que traz como título o enunciado "Como se tornar um infografista", a revista fala sobre dois aspectos a respeito da infografia: um deles diz respeito à formação profissional, mercado de trabalho, perfil do profissional etc.; o outro, a como fazer uma infografia ${ }^{11}$. Com relação ao primeiro aspecto, a revista trata de aproximar ao máximo, a si própria, o leitor, logo no primeiro item.

Não existe graduação em infografia. A maioria dos profissionais nesta área é formada em jornalismo ou design. Na verdade, embora na ME [Mundo Estranho] você sempre ouça falar de infográficos e veja um monte deles a cada edição, a infografia ainda é uma das áreas menos desenvolvidas do jornalismo, tanto nas redações quanto nas universidades (PORTILHO, 2008, 20. Grifos nossos).

\footnotetext{
${ }^{9}$ Mundo Estranho deriva da coluna "Superintrigante", publicada pela Superinteressante desde 1987, e que respondia perguntas de leitores. Foram três edições especiais (entre 2001 e 2002) e a periodicidade mensal a partir do quarto número, em 2003.

${ }^{10}$ Ambas as revistas, da Editora Abril, tinham Luiz Iria como editor de infografias à época.

${ }^{11}$ A revista usa indistintamente os termos "infografia" e "infográfico".
} 


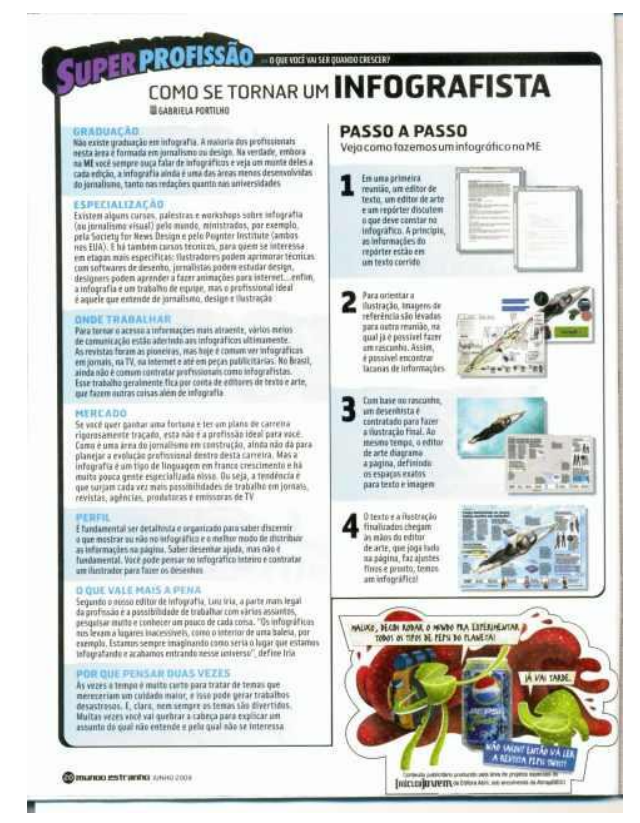

Figura 2 - A página de Mundo Estranho

Assim, a revista propõe um vínculo de conhecimento entre ela e o seu leitordestinatário: este sabe o que é uma infografia, porque sempre ouve falar deles e sempre os vê/lê. A lógica que aqui se institui é a da "manutenção do contrato": dizer que o leitor de Mundo Estranho desconhece o que é uma infografia é um risco; ao mesmo tempo, a revista diz que a infografia "é uma das áreas menos desenvolvidas do jornalismo", o que produz um efeito de distinção da revista (em relação aos demais produtos e veículos jornalísticos) e do leitor (em relação ao leitor dos demais produtos e veículos jornalísticos). Por outro lado, o caráter didático-descritivo está totalmente presente na parte referente ao "passo a passo" sobre a infografia, numerada em quatro partes: 1) reunião entre editor de texto, editor de arte e repórter, 2) uso de imagens de referência, 3) feitura de um rascunho e 4) finalização da infografia. Apesar do caráter didáticodescritivo, há um "clima” que mescla descontração e prazer ao final do texto.

1. Em uma primeira reunião, um editor de texto, um editor de arte e um repórter discutem o que deve constar no infográfico. A princípio, as informações do repórter estão em um texto corrido. 2. Para orientar a ilustração, imagens de referência são levadas para outra reunião, na qual já é possível fazer um rascunho. Assim, é possível encontrar lacunas de informações. 3. Com base no rascunho, um desenhista é contratado para fazer a ilustração final. Ao mesmo tempo, o editor de arte diagrama a página, definindo os espaços exatos para texto e imagem. 4. O texto e a ilustração finalizados chegam às mãos do editor de arte, que joga tudo na página, faz ajustes finos e pronto, temos um infográfico! (PORTILHO, 2008, 20. Grifos nossos). 


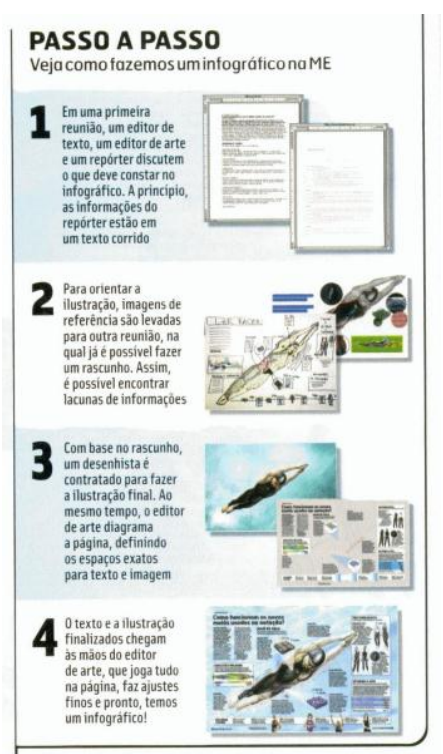

Figura 3 - Detalhe de infografia autorreferencial (Mundo Estranho)

De um lado, o caráter didático-professoral, cuja enunciação estabelece-se tendo por base o eixo "eu-ele/isto" (sujeito enunciador/“eu" fala sobre algo/“isto" para um "tu" não presente textualmente na superfície da sua fala), fica claro em passagens como “o editor de arte diagrama a página, definindo os espaços exatos para texto e imagem". De outro lado, temos uma espécie de mudança metaléptica de nível enunciativonarrativo, na qual o sujeito enunciador deixa de "falar sobre algo sem um tu" e passa a se dirigir implicitamente para um $t u$ (novo eixo: "eu-tu"): assim, surge o verbo "ter" na primeira pessoa do plural, de modo inclusivo, ao encerramento do texto: "e pronto, temos um infográfico!". Esse verbo "temos" estabelece um outro vínculo, que é o da ideia de participação, do compartilhar o modo de fazer e funciona numa lógica distinta à do subtítulo do espaço: "Veja como fazemos um infográfico na $M E$ ", cujo "nós" ("nós", da $M E$ ) oculto é de exclusão (do outro). Assim, o leitor de Mundo Estranho é ensinado e, ao mesmo tempo, tem (num primeiro momento) o resultado final da "aula" em suas mãos - a própria revista - e (o que, em tese, não sabe) ele encontrará, num segundo momento, algumas páginas adiante, a mesma infografia usada na explicação, o que permite que ele mesmo, leitor, possa comparar o processo de feitura e o resultado infográfico final. A infografia é, simultaneamente, uma oferta da publicação, uma "descoberta" a dois (sujeito enunciador e destinatário) e, enfim, um aprendizado que torna a ambos, jornalista e leitor, "parceiros". Em suma: "é fazendo que ensinamos a fazer". 
O curioso é que, apesar de revistas como Mundo Estranho darem ênfase ao uso visual de textos e imagens, neste caso o agente enunciador priorizou as instâncias de narração em detrimento das instâncias de mostração. Narra-se muito, mostra-se pouco. Esses aspectos ficarão mais claros quando comparados com o exemplo a seguir.

\section{O texto influenciado pela infografia: "aqui falamos e mostramos o que você não sabe"}

Nosso outro exemplo é extraído do site jornalístico $G 1$, pertencente às Organizações Globo e disponibilizado na Internet em 22 de setembro de 2007 (figura 4). A ideia que é passada aqui, para a feitura de infografias animadas, é que o trabalho é árduo, mas recompensador - vide o título ("Veja como o G1 produz seus infográficos") combinado com o subtítulo ("caminho é longo para a criação das animações que enriquecem as reportagens. Confira como toda a magia acontece nos bastidores").

Apesar desse exemplo não se caracterizar como uma infografia (pois o que temos é um texto entrecortado por várias imagens), sua construção visual se assemelha muito mais ao universo das infografias do que o dos textos escritos ilustrados (como dissemos antes, a estética infográfica vem influenciando o desenho jornalístico). Poderse-ia objetar, ainda, que o exemplo em questão vem do universo do eletrônico-digital, e não do impresso; porém, do modo como ele aparece estruturado no site de $G 1$, a única diferença pertinente em relação à questão dos suportes é a existência dos links, inclusive para a matéria cuja infografia é "decomposta". 


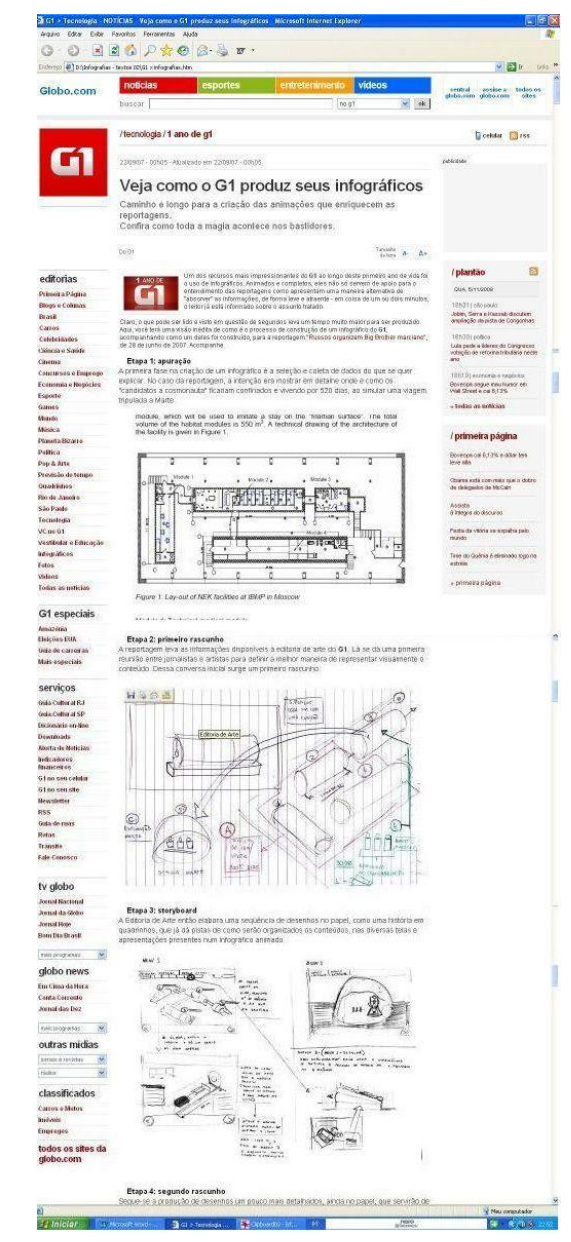

Figura 4 - Detalhe de página do site do $G 1$

Além disso, na prática, em quase nada ele se distingue de outros tipos de produção textual jornalística que mostram "como algo é feito" ou "como algo acontece". A diferença é justamente que esse "algo" é o próprio modus operandi jornalístico. A inclusão desse exemplo se justifica pelo fato de que (a nosso ver) ele faz parte do universo de discursos constituídos a respeito da infografia. Mais do que falar sobre como uma infografia é feita, esse texto enuncia algo mais: que essa magia não é a das infografias animadas em si, mas a magia das infografias de $G 1$.

Curiosamente, o texto do $G 1$ assume para si (e, por extensão, para a Internet) aquilo que outrora cabia à televisão: ser o espaço da magia, o espelho ou a caixa mágica que trazia o mundo para a casa do espectador, ao mesmo tempo em que "abre as portas" dos seus bastidores para o leitor ver algo "inédito" (ou seja, obedecendo a um dos tradicionais critérios de noticiabilidade, no caso o ineditismo), ao mesmo tempo impressionante, leve e atraente. Isso fica claro desde o título e o subtítulo da matéria e continua no lide e no sublide. 
Um dos recursos mais impressionantes do G1 ao longo deste primeiro ano de vida foi o uso de infográficos. Animados e completos, eles não só servem de apoio para o entendimento das reportagens como apresentam uma maneira alternativa de "absorver" as informações, de forma leve e atraente - em coisa de um ou dois minutos, o leitor já está informado sobre o assunto tratado (...). Claro, o que pode ser lido e visto em questão de segundos leva um tempo muito maior para ser produzido. Aqui, você terá uma visão inédita de como é o processo de construção de um infográfico do G1, acompanhando como um deles foi construído, para a reportagem "Russos organizam Big Brother marciano", de 28 de junho de 2007. Acompanhe (G1, 2007. Grifos nossos).

Aqui, a noção de vínculo se estabelece de modo distinto em relação a Mundo Estranho. Se no primeiro havia uma proximidade "escolar" entre agente enunciador e destinatário, no G1 o clima é diferente: o vínculo é o da relação jornalista-leitor, sendo que o primeiro vai mostrar ao leitor os bastidores da produção de uma infografia, algo em tese "inédito" e a ser acompanhado. Predomina a ideia da mídia-olho, aquela que tudo visibiliza, tudo em nome do espectador/leitor, que deve "acompanhar" o percurso que será mostrado.

Se o exemplo anterior dividia o processo de feitura de uma infografia em apenas quatro partes (o que fazia tudo parecer algo simples), aqui o processo tem o dobro de etapas (oito: apuração, primeiro rascunho, storyboard, segundo rascunho, modelagem em 3D, texturização e renderização, programação e animação e, por fim, revisão e publicação). Somente o número de etapas e os modos de denominá-las bastaria para denotar ao leitor a ideia de que o processo é, realmente (ao menos no G1), longo, complicado e que requer um profissional especializado, principalmente por conta do uso de termos pouco usuais ao leitor leigo em informática (modelagem, texturização, renderização); porém, o modo como o processo é mostrado também se torna relevante.
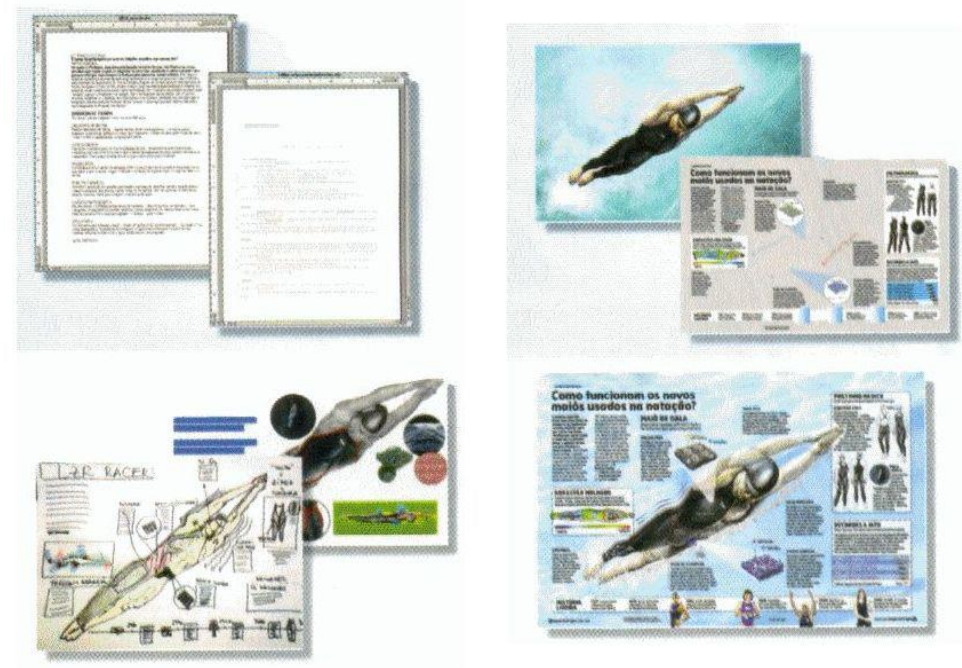

Figura 5 - Detalhes das imagens da infografia de Mundo Estranho 
Em $M E$, o conjunto de imagens usadas para ilustrar o processo infográfico é reduzido e simplificado (figura 5), quando comparado com o conjunto de imagens do G1 (figuras 7, 8, 9). No primeiro caso, quase não há destaque visual para elas; no segundo, o grau de detalhamento mostra outros aspectos do processo enunciativo em G1.

Se em $M E$ as imagens parecem cumprir papel meramente ilustrativo (não dá para perceber certos detalhes nas imagens, nem há tanta nitidez nelas), em $G 1$ ocorre o oposto: elas denotam a qualificação dos profissionais que trabalham na área. A primeira imagem da matéria (figura 6), que ilustra a etapa "apuração", mostra o que parece ser o esboço original do desenho de uma espaçonave: o texto em volta do desenho técnico está em inglês (o que conota a ideia de uma informação de "primeira mão") e, apesar de ter sido editado visualmente (não vemos o texto em sua totalidade), encontramos números $\left(550 \mathrm{~m}^{3}\right)$, siglas ("NEK", "IBMP") e termos "técnicos" ("module", "a technical drawing of the architecture of the facility..."). Ou seja: não é apenas uma imagem de referência (como ocorre em $M E$ ), mas uma imagem técnica, com grande grau de abstração (já que, a princípio, ela não se parece com algo existente no mundo real), e que serve de suporte para a produção das imagens infográficas jornalísticas. A escolha dessa imagem, por tudo que dissemos, deixa claro o tipo de imagem de agente enunciador aqui instituída: um profissional que domina tanto a leitura de imagens técnicas quanto a leitura do idioma e dos termos técnicos que nela aparecem. O texto que a acompanha diz: "a primeira fase na criação de um infográfico é a seleção e coleta de dados do que se quer explicar. No caso da reportagem, a intenção era mostrar em detalhe onde e como os 'candidatos a cosmonauta' ficariam confinados e vivendo por 520 dias, ao simular uma viagem tripulada a Marte".

module, which will be used to imitate a stay on the "Martian surtace". Ine total
volume of the habitat modules is $550 \mathrm{~m}^{3}$. A technical drawing of the architecture of volume of the habitat modules is
the facility is given in Figure 1 .

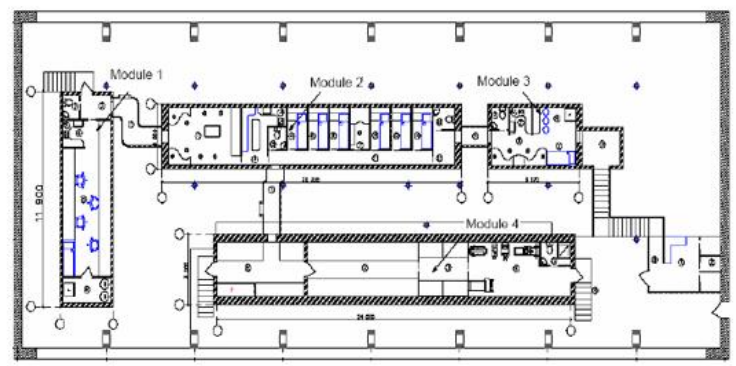

Figure 1: Lay-out of NEK facilities at IBMP in Moscow 
Figura 6 - imagem técnica de espaçonave

$\mathrm{Na}$ etapa seguinte, "primeiro rascunho" (figura 7), o clima visual muda: surge um esboço feito em papel pautado e desenhado a caneta, em diferentes cores (que parecem sugerir "diferentes etapas do processo de feitura do esboço"). Se o desenho anterior primava por seu clima visual "técnico" (com ângulos e linhas retas), o esboço segue numa direção oposta: o conjunto de linhas curvas, setas curvilíneas, retas irregulares, passam a ideia de "brainstorm", de algo que foi esboçado por um desenhista, sugerindo um certo grau de espontaneidade e de relaxamento (afinal, é um esboço ainda). Há o predomínio da ideia de dinamismo, em relação à estaticidade visual do desenho anterior. O grau de abstração é menor do que na ilustração anterior, mas ainda assim é considerável.

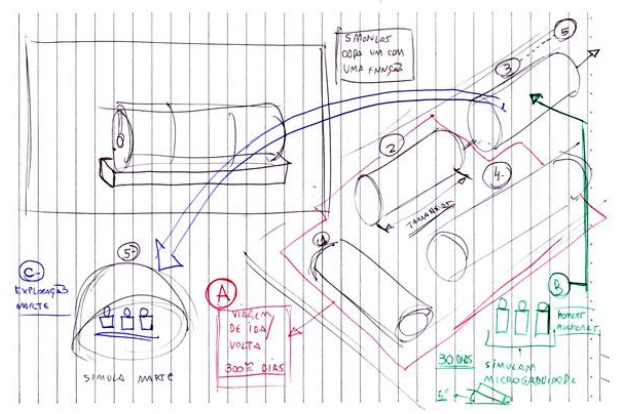

Figura 7 - esboço de desenho usado na infografia de $G 1$

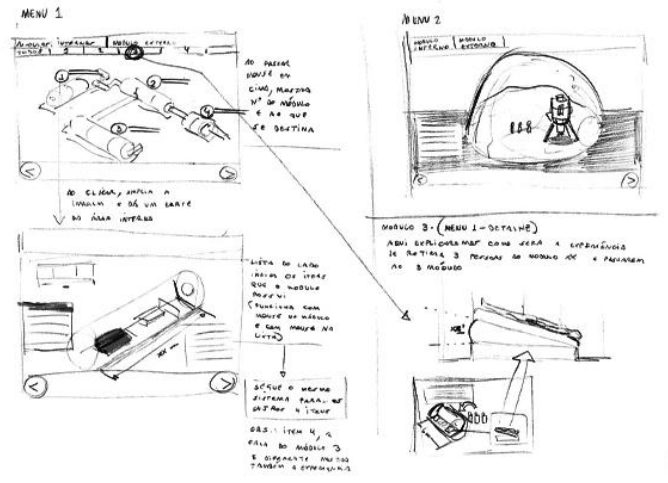

Figura 8 - storyboard da futura infografia animada do $G 1$

Já em "storyboard” (figura 8), o clima espontâneo ainda predomina, mas agora surge um novo elemento: a sequencialidade narrativa. Temos um conjunto de quatro quadros cujos conteúdos são distintos entre si, o que sugere diferentes tempos e/ou espaços aí representados. Mesmo assim, a lógica supostamente sequencial dos quatro quadros é rompida por uma seta que atravessa o conjunto de cima para baixo, da 
esquerda para a direita. Ou seja: o esboço ainda está sendo trabalhado, não é definido logo na primeira tentativa. Do ponto de vista enunciativo, nosso exemplo mostra-se curioso: o sujeito metaenunciador (responsável pelo todo jornalístico em questão: a matéria do Gl) mostra como o sujeito articulador (responsável pelo esboço da infografia) começa a estabelecer os vínculos lógico-narrativos entre as diferentes imagens; do ponto de vista narrativo, o sujeito enunciador mostra um instante que ele julga pertinente, que é a etapa de articulação.

Segue-se a esse storyboard um "segundo rascunho" (figura 9) que servirá de referência para a versão digital do desenho; esse segundo rascunho se apresenta mais bem acabado do que o primeiro, com o desenho apresentando traços mais firmes, uma maior quantidade de linhas retas, e ideias visuais mais bem definidas de tridimensionalidade e volume, graças principalmente aos sombreamentos; o desenho que aqui temos funciona como uma espécie de "meio termo" entre o desenho técnico da figura 6 e o esboço da figura 7, ou seja, entre a rigidez de um e o caráter "relaxado" do outro.

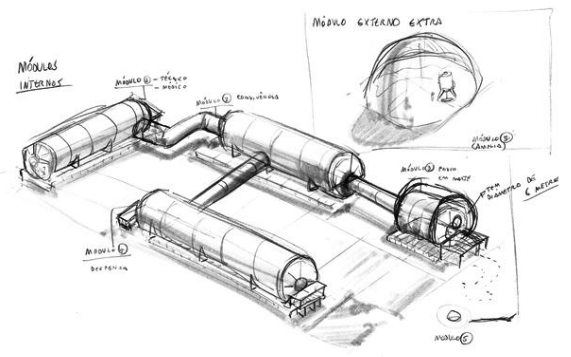

Figura 9 - esboço mais bem-acabado para a infografia de $G 1$

Não vamos mais nos alongar neste exemplo: cremos que foi possível mostrar que essas dois textos autorreferenciais criam diferentes imagens de seus enunciadores ${ }^{12}$. Em $M E$, o clima é mais "relaxado", de proximidade com o leitor, e o próprio conjunto de imagens usadas para ilustrar o passo a passo da revista transparece essa simplicidade; em $G 1$, a produção de uma infografia é algo efetivamente trabalhoso e demorado (a página traz, ao todo, 12 imagens diferentes), e que, ao mesmo tempo, parece ser feito por profissionais altamente qualificados. Em $M E$, o infógrafo poderia ser o próprio leitor (aquele que busca uma futura profissão); em G1, o infógrafo é um especialista; na

\footnotetext{
${ }^{12}$ Cumpre lembrar que o texto de Mundo Estranho está inserido em uma seção fixa da revista; esse fato, obviamente, não impede o seu caráter autorreferencial.
} 
verdade, para ser mais preciso, um jornalista que aponta para um fazer ver, e que acaba trazendo ao leitor uma "novidade" (figura 10), que é uma sequência de imagens que não fora utilizada anteriormente: "abaixo, por exemplo, veja uma sequência de imagens que mostram detalhes dos módulos 'marcianos' que acabaram não aparecendo no infográfico finalizado" (grifos nossos).

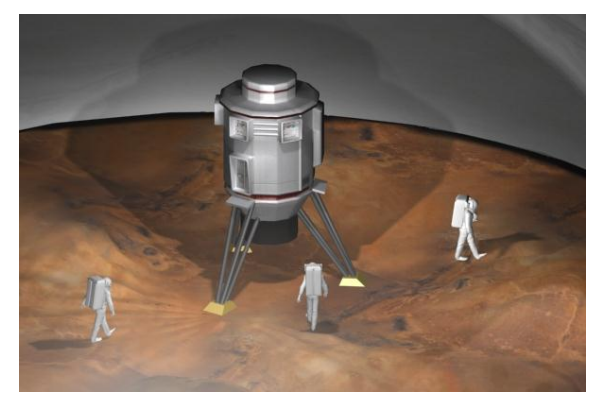

Figura 10 - uma das imagens não usadas na infografia de $G 1$

Ao final, e para reforçar a imagem do enunciador que faz ver, o enunciado final da infografia: "confira agora a versão final do infográfico que serviu de exemplo para esse passeio pelos bastidores da Editoria de Arte do G1". Se em $M E$ temos uma relação complementar que busca se tornar (por via da enunciação) uma relação simétrica, em G1 temos uma situação oposta: na Internet, um espaço supostamente simétrico, G1 propõe um vínculo simbólico-enunciativo assimétrico: "eu vejo e lhe mostro, você só observa". Assim, podemos dizer que essas infografias terminam também por instituir diferentes ethoi de seus agentes enunciadores: o primeiro, próximo, simpático, quase centrado no pathos; o segundo, mais distante, quase que totalmente focado no logos. Porém, a partir da comparação entre ambas, percebe-se um ethos relaxado (no primeiro caso) e um ethos qualificado (no segundo caso); não é preciso falar de si, basta exibir o tom de sua enunciação.

Além disso, no plano narrativo, o enunciador do material de $G 1$ opta por alternar entre a narração das etapas do processo de feitura de uma infografia e a mostração de imagens que visualizem essas mesmas etapas, tenham sido elas usadas ou não. Assim, fica claro para o leitor (no espaço de G1) a noção de edição, ou seja, de que nem todo material bruto obtido e/ou produzido pela redação é utilizado de fato. Mais uma vez, uma modalidade do fazer jornalístico (a edição) é trazida à tona.

Aqui, fica claro que a imprensa contemporânea não tem problemas em trazer à tona alguns aspectos da produção de seu discurso. Verón $(1980,80)$, ao se referir aos 
três níveis de intertextualidade, falava do terceiro nível, o dos discursos ocultos, aqueles que não atingem a superfície textual mas que estão de algum modo presentes na constituição do texto em questão. Aparentemente, o movimento discursivo que G1 faz é o de "desocultizar" um modus operandi seu (o fazer infográfico) através do movimento de visibilizar como uma infografia é feita. Ao permitir ao leitor que este "descubra" algo da "esfera privada" do site (que é "público", pois está na Internet), G1 estabelece (ou reforça) uma espécie de vínculo de cumplicidade. Na prática, porém, a intertextualidade oculta, que não atinge a superfície textual, continua lá, oriunda dos manuais de redação e de fotojornalismo, e de outras publicações do gênero.

\section{Considerações finais}

A análise apresentada quis mostrar como o recurso infográfico tem permitido aos jornais não apenas descrever fatos ditos "invisíveis" ou visualizáveis, mas também ajudam a aumentar o grau de autorreferencialidade deles mesmos. Como o texto infográfico é percebido, muitas vezes, como uma espécie de enunciado objetivo e científico, é natural que essas "propriedades" ajudem a influenciar na percepção que os leitores têm do sistema midiático. Se o homem tornou-se objeto de pesquisa e análise na Modernidade, na Contemporaneidade é o sistema midiático que se torna não apenas presente, mas também representável, visibilizável, analisável, cujos modos de produção da notícia são esquematizáveis.

Até certo ponto, essas práticas ajudem a explicar porque a mídia (ou ao menos parte dela) é considerada uma instituição idônea: ela não só fala de outras instituições como também pode falar de si própria, com os mesmos "métodos" usados para se referir a outras instituições e/ou situações sociais. Não só a mídia fala do mundo; ela também faz parte do mundo e lembra isso ao leitor. A mídia se torna um novo parâmetro de si própria, torna-se signo e discurso de si própria: não mais apenas mostro isso, logo isso existe, mas também me mostro, logo existo.

\section{Referências}

BATESON, G. Vers une Écologie de l'Esprit. Tome 1, Paris: Seuil, 1977.

CHARAUDEAU, P. Discurso das Mídias. São Paulo: Contexto, 2006. 
FAUSTO NETO, A. "Mutações nos Discursos Jornalísticos: da 'construção da realidade' à 'realidade da construção"'. In: FELIPPI, Ângela, SOSTER, Demétrio de Azeredo \& PICCININ, Fabiana. Edição em Jornalismo: ensino, teoria e prática. Santa Cruz do Sul: Edunisc, 2006.

FERGUSON, R. Los Medios bajo Sospecha - ideología y poder en los medios de comunicación. Barcelona: Gedisa, 2007.

GOMIS, L. Teoría del Periodismo: cómo se forma el presente. Barcelona: Paidós, 1997.

G1. "Veja como o G1 produz seus infográficos". In: G1. 22 de setembro de 2007. Disponível em http://g1.globo.com/Noticias/Tecnologia/0,,MUL106298-6174,00.html.

LEJEUNE, P. Le Pacte Autobiographique. Paris: Seuil, 2002.

LOCHARD, G. \& BOYER, H. La Comunicación Mediática. Barcelona: Gedisa, 2004.

LUCAS, R. J. de L. "Infografia: substituta progressiva do fotojornalismo?". In: Estudos em Jornalismo e Mídia, v. 7, 2010, p. 87-98.

MOUILlAUD, M. \& PORTO, S. D. (org.) O Jornal - da forma ao sentido. Brasília: Paralelo 15, 1997.

PORTILHO, G. "Como se tornar um infografista". In: Mundo Estranho. São Paulo: Ed. Abril, n. 76, junho de 2008, p. 20.

RINCÓN, O. Narrativas Mediáticas: o cómo se cuenta la sociedad del entretenimiento. Barcelona: Gedisa, 2006.

VATTIMO, G. A Sociedade Transparente. Lisboa: Ed. 70, 1991.

VERÓN, E. A Produção de Sentido. São Paulo: Cultrix, 1980.

Recebido em: 25 de maio

Aprovado em: 30 de julho 